\title{
Combined anatomical and radiological study of the hip-joint in alcaptonuric arthropathy
}

\author{
U. STEI GER AND R. LA GIER
}

From the Medical Clinic, University of Basel, and the Department of Pathology, University of Gencva $\mathrm{CH}$ - 1211 Geneva, Switzerland

In two patients with alcaptonuric arthropathy, we have had the opportunity of investigating three femoral heads which had been surgically removed to be replaced by a total prosthesis. This allowed us to study the osteoarthrotic remodelling of epiphyses in which damaged cartilage is labelled by pigment. This exceptional condition facilitates study of the fate of this cartilage among newly-formed tissues.

\section{Case reports}

Case 1, a 64-year-old woman, was one of four cases of ochronosis in a family of nine siblings which one of us has previously reported (Steiger, 1963). The course of the disease and the clinical and $x$-ray findings in all affected siblings were characteristic and in accordance with the literature (Cervenansky, Sitaj, and Urbanek, 1959; O'Brien, Banfield, and Sokoloff, 1961).

The hip-joints of this patient appeared normal by clinical and radiological examination until March, 1967, when she suffered an acute onset of severe pain in the right hipjoint. On March 8 an $x$-ray examination showed narrowing of the joint space with complete obliteration by April 21, and severe destruction of the articular surfaces without appreciable osteophytic reaction in September (Fig. 1).

Accepted for publication January 21, 1972.
Changes on the left side followed a similar pattern. The first signs, slight narrowing of the interarticular space, were observed in April, 1967. In the course of a year, this narrowing increased with marked flattening of the femoral head, without appreciable osteophytic reaction (Fig. 2). Because of severe pain and the inability of the hip-joints to bear weight, the femoral heads were removed and replaced by total prostheses.

\section{Pathological findings}

The head of the right femur showed complete disappearance of the cartilage in the weight-bearing zone (Figs $3 a$, $b, 4 a$ ). The exposed underlying bone appeared white and eburnated with some erosions covered with connective tissue. This remodelling led to a superficial abrasion explaining the flattening of the femoral head. Outside the weight-bearing zone the black cartilage surface was preserved without obvious osteophyte formation. In the synovial tissue some black spots corresponded to cartilaginous grafts. In the ligaments some black areas were due to pigment impregnation. These changes were shown on radiography of the head in the form of superficial bone sclerosis and an ill-defined superior margin (Fig. $4 b$ ).

Macroscopical (Fig. 4a) and histological sections through the centre of the head showed a sharp distinction between the weight-bearing and non-weight-bearing
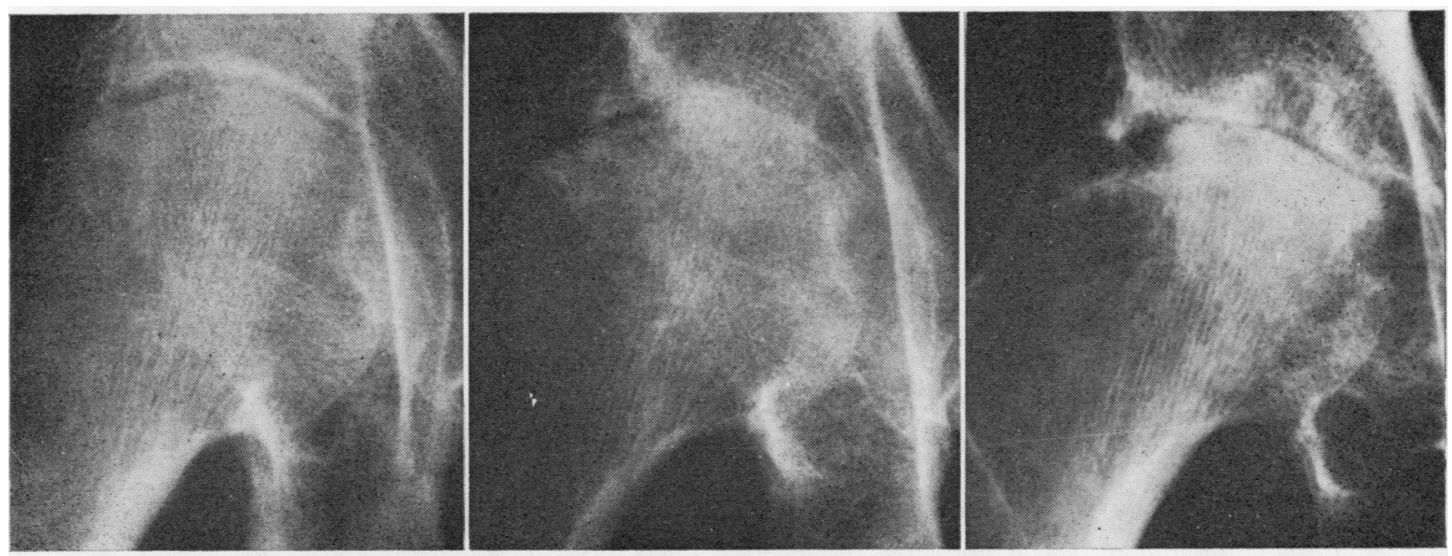

FIG. 1 Case 1. Right femoral head, showing rapid disappearance of joint space and destruction of femoral head in 1967. March 8 (a), April 21 (b), and September 7 (c) 

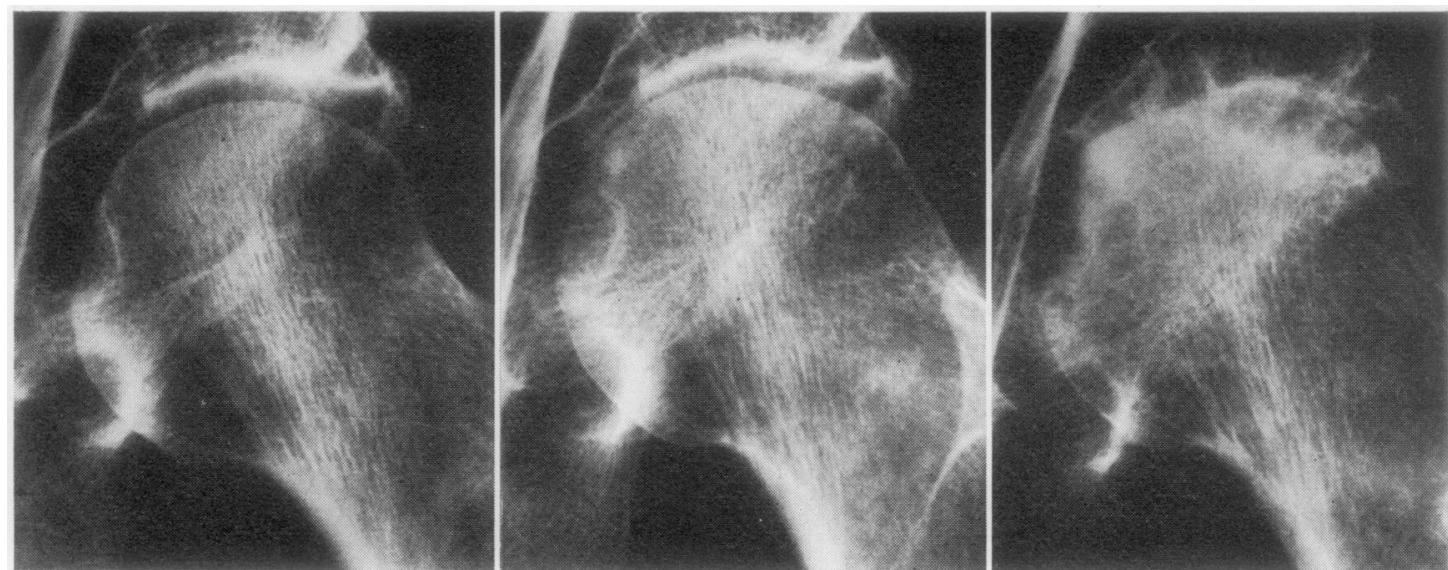

FIG. 2 Case 1. Left femoral head, showing progressive destruction of cartilage between June 26, 1962 (a), September 7, 1967 (b), and May 20, 1968 (c)
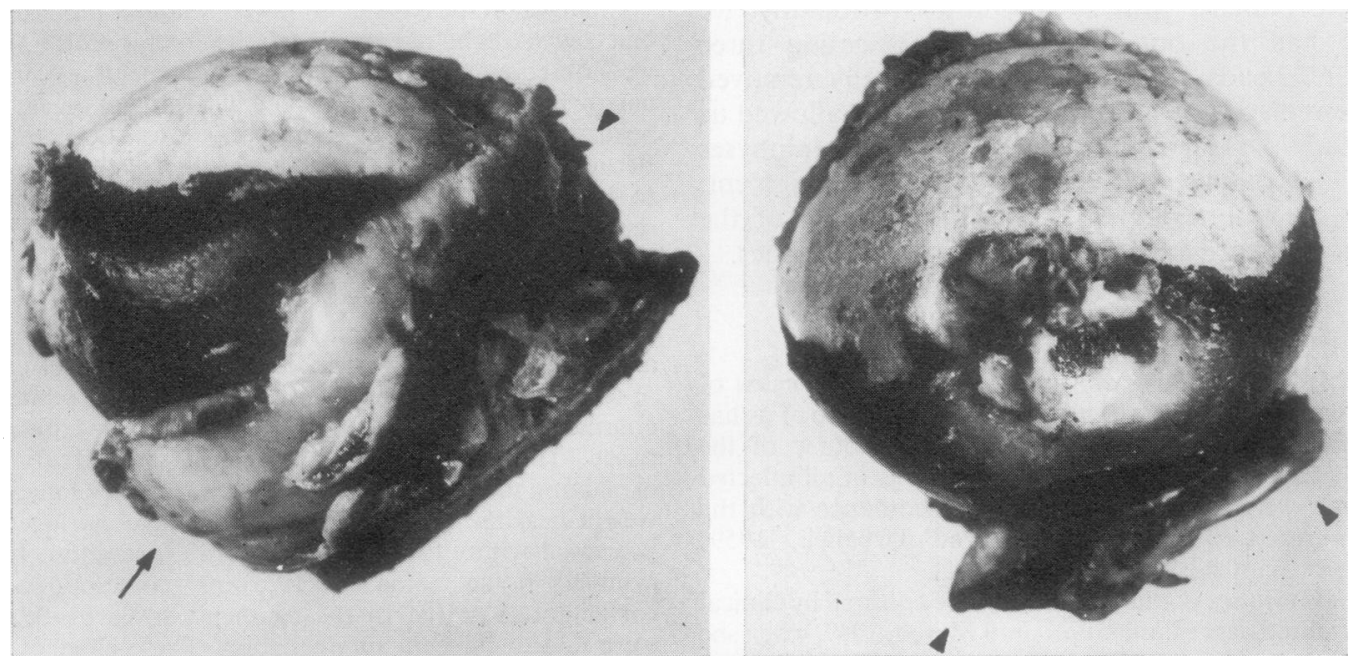

FIG. 3 Case 1. Right femoral head (a) Posterior view. (b) Medial view. The cartilage (black) is abraded in the weight-bearing zone leaving a bare, eburnated, and flattened underlying femoral head. A marginal overgrowth of non-pigmented hyperplastic synovium represents an extrinsic element of this osteoarthrotic remodelling, and thus can be considered as an equivalent of osteophyte $(\rightarrow)$. Some islets of pigmented cartilage splits grafted in the synovium are visible as black areas ( )
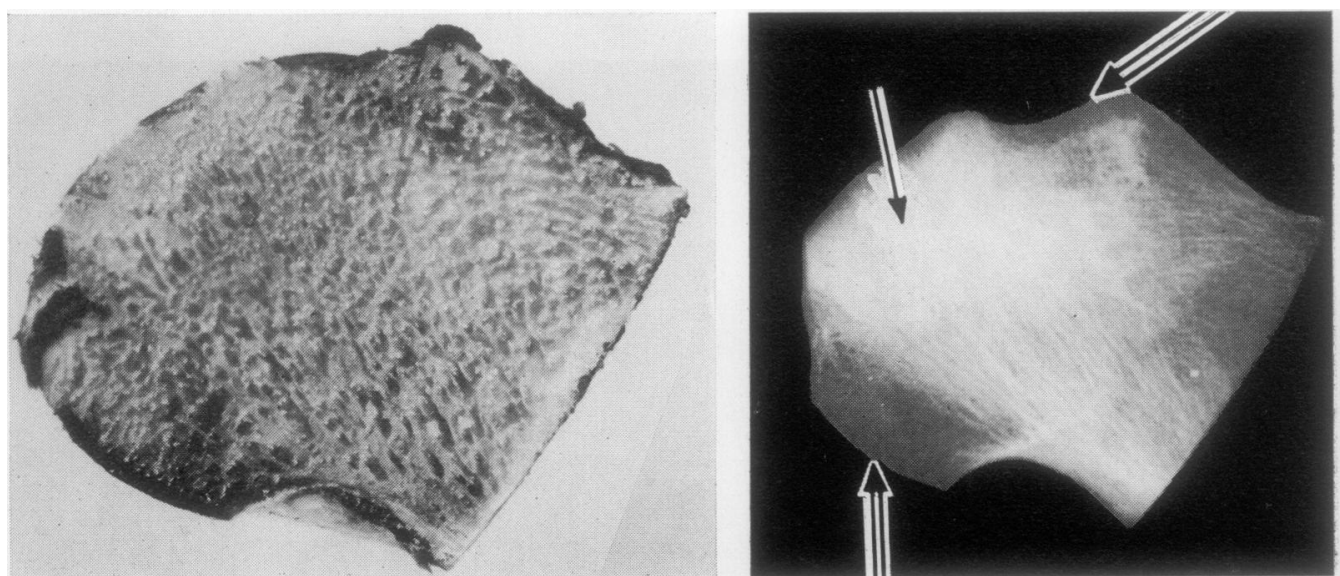

FIG. 4 Case 1. Sagittal section of preceding specimen (T 12638/67). (a) Macroscopic view. Pre-existing pigmented cartilage remains in the non-weight-bearing zones, i.e. supero-lateral and infero-medial (infra-foveolar); some pigmented tissue (cartilaginous splits or ligamentous bundles) remains in the fovea as well as in the periosteum. (b) $X$ ray of (a) 


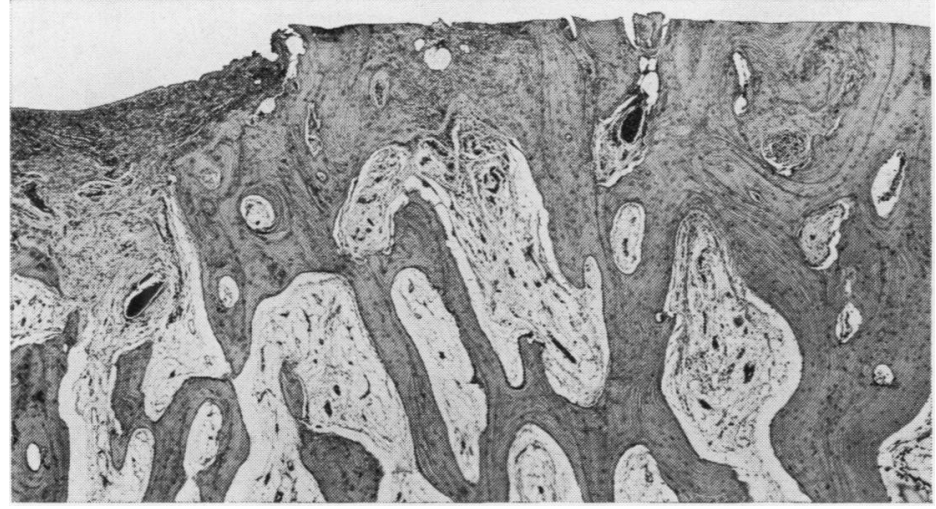

FIG. 5 Case 1. Section through abraded bone in weight-bearing zone. Eburnated bone is interrupted in some parts by craters over-run by vascularized connective tissue. Some pigmented fragments of cartilage are embedded in the remodelled bone. Haematoxylin and eosin. $\times 25$

zones. In the latter the cartilaginous pigmented surface remained and the underlying bone was osteoporotic. In the overloaded part, the remodelling of the exposed bone showed changes well known in osteoarthrosis (Fig. 5). The brittle cartilage formed 'spangle-like' pieces, which were occasionally embedded in the marrow of the remodelled bone, but chiefly grouped or isolated in the synovium or periosteum. Some were phagocytosed by histiocytes and giant cells acting as chondroclasts and containing numerous pigment granules. They induced a more or less pronounced synovial hyperplasia, but little inflammatory cellular reaction was displayed despite considerable deposition of cartilage fragments. Some islets of newly-formed metaplastic bone or cartilage were found. Unstained sections show the yellow ochre of the pigmented cartilage, the origin of the term 'ochronosis' coined by Virchow (1866), who gave the classical pathological description of this condition.

The anatomical examination of the left femoral head revealed the same changes as on the right side but less severe (Fig. 6). The cartilage was not completely destroyed in the weight-bearing zone and the flattening of the femoral head was minimal.
Case 2*, a 63-year-old man had suffered from ochronotic arthropathy for many years. At the age of 51 an open biopsy of the right hip was taken at the time of a "forage" (cyst drilling and curettage). On this occasion the surface of the femoral head was found to be entirely black. A marginal osteophyte was seen to be covered by nonpigmented newly formed fibro-cartilage. Histologically this biopsy showed many 'spangle-like' fragments of pigmented cartilage, either distributed in groups (Fig. 7a) or isolated in the fibrous connective tissue. In some places islets of newly formed metaplastic cartilage and bone were seen (Fig. 7b).

The same femoral head provided an interesting example of arthrotic remodelling (Fig. 8) when it was removed 12 years later to be replaced by a total prosthesis: of chief interest was the fact that only pre-existing cartilage was pigmented. This disappeared completely and persisted only in the form of black remnants buried beneath osteophytes. The newly formed fibro-cartilaginous surface was not pigmented. In addition, chondrocalcinosis was found in the synovial fringes (calcium-pyrophosphate dihydrate crystals, demonstrated by $x$-ray diffraction).

*Patient of Dr. B. Montmollin, Neuchâtel, to whom we are grateful for permission to publish this case.
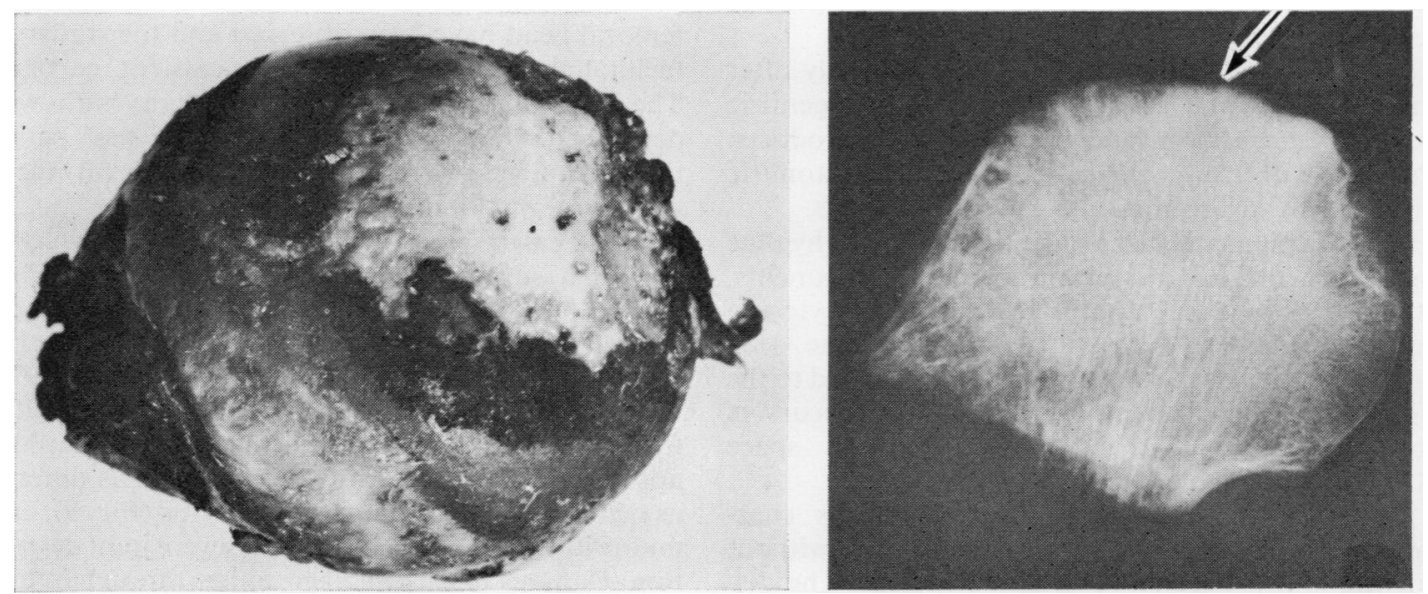

FIG. 6 Case 1. Left femoral head (T 9662/70). (a) Postero-superior view of cartilaginous lesions similar to those in Fig. 3.

The arthrotic remodelling is less pronounced. $(b) X$ ray of $(a)$ 

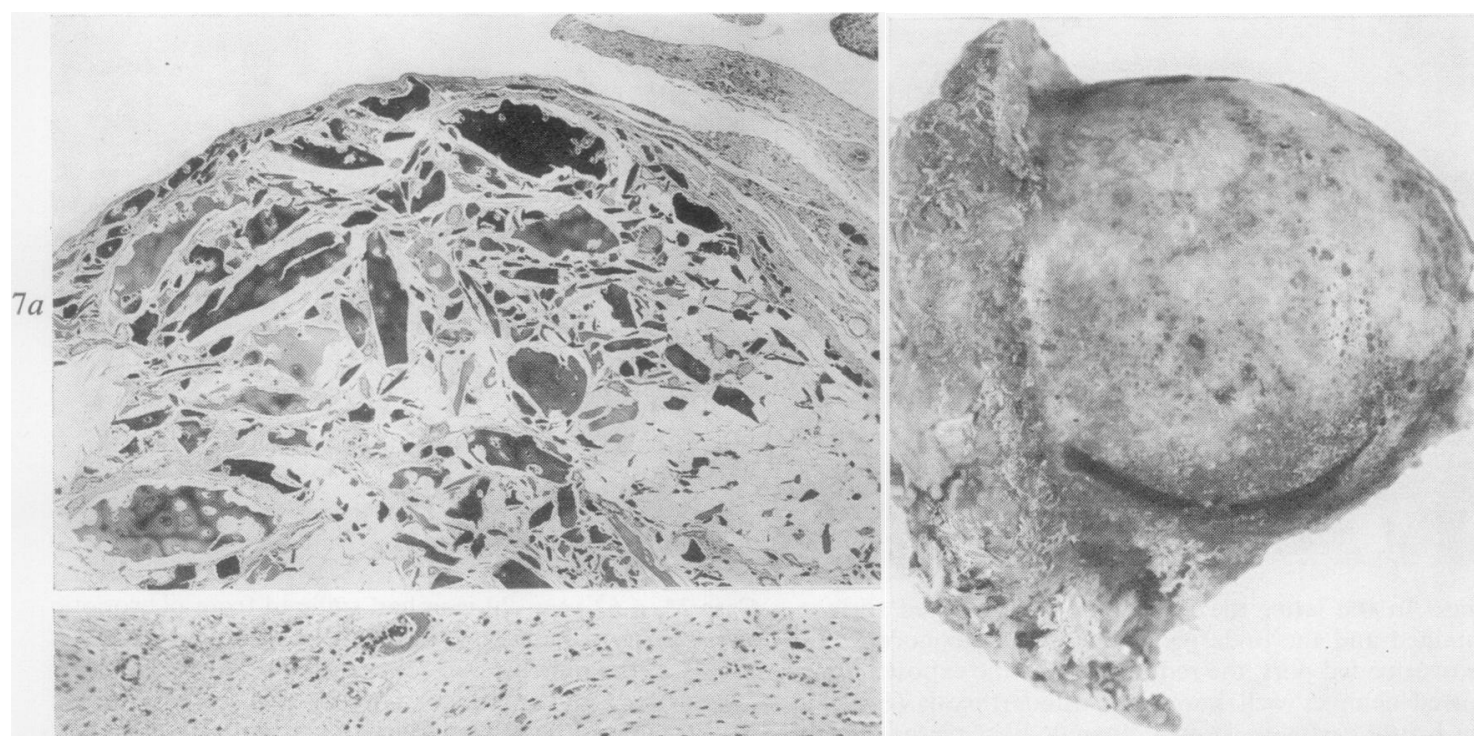

FIG. 8 Case 2. (T 3437/68). Postero-superior view of right femoral head. All the pigmented cartilage is abraded except for remnants buried beneath osteophytes. Chondrocalcinosis is present in synovial fringes

FIG. 7 Case 2. (T 299/57). (a) Considerable⿳⺈ deposition of split-off portions of cartilage, grafted. in a fatty synovial fringe. Haematoxylin and eosin. $\times$ 25. (b) Cartilaginous and bony metaplasia with two small fragments of pigmented cartilage in fibrotic synovial membrane. Haematoxylin-eosin. $\times 79$

\section{Discussion}

The examination of these two cases of alcaptonuric arthropathy with the pathological study of three femoral heads demonstrates the following general aspects of ochronosis:

(1) Cartilage deterioration is observed only after long exposure and impregnation with homogentisic acid or its oxidation and polymerization products. Parallel with this, clinical signs of alcaptonuric arthropathy are seen as late as 50 to 60 years.

(2) The pigment is seen only in pre-existing hyaline or fibro-cartilage and in certain layers of the ligaments. It is absent in tissue except in cells phagocytosing cartilage. Pigment is grossly confined to the deep layers of articular cartilage, presumably related to the direction of the flow of pigment or its precursors from the bone marrow towards a joint space (O'Brien, La Du, and Bunim, 1963).

(3) The deterioration of the cartilage is characterized by brittleness and fragmentation, without fraying and proliferation of chondrocytes. The displaced fragments can be included in the remodelling of the weight-bearing zone. They are chiefly grafted into the synovium, inducing a fibrous reaction and sometimes a cartilaginous or bony metaplasia.

Three forms of osteoarthrotic remodelling of the femoral head have been observed and the study was facilitated by labelling the pre-existent cartilage. The second patient shows a late form with welldeveloped osteophytes, whereas in the first patient the osteophytes were only found by careful microscopic examination.

These cases show different stages of the remodelling of a still mobile joint, in which the cartilage surface had suffered in the course of a systemic disorder, and not for a local mechanical reason, such as is seen after dysplasia of the hip-joint (Lagier, 1971).

It is thus not surprising that the overall result of this remodelling (and consequently its radiographical appearance) is similar in two conditions as different as ochronosis and rheumatoid arthritis (Fig. 9), even taking into account the rapid and severe joint destruction. Damage to the cartilage, either through inflammation or through metabolic disturbance, may also contribute to the pathogenesis of these destructive 

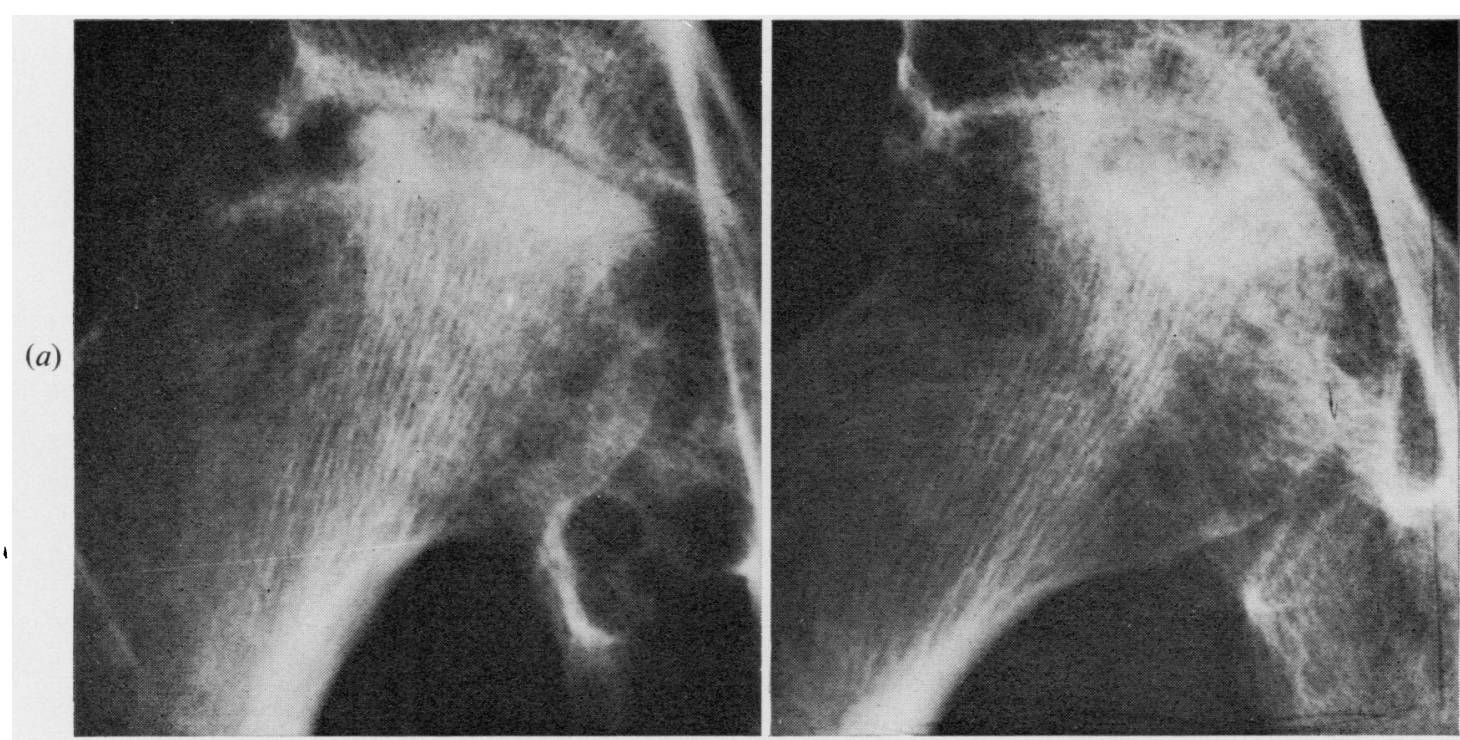

(b)

FIG. 9 Similar $x$-ray images can be observed in alcaptonuric arthropathy (a) and rheumatoid arthritis $(b)$ with complete destruction of the cartilage in the weight-bearing zone

joint conditions. Thus alcaptonuria, a rare inborn error of metabolism, offers the opportunity of studying certain basic elements of joint pathology.

\section{Summary}

The radiological and anatomical findings in three hip-joints in two alcaptonuric patients showed destruction and joint remodelling caused by deterioration of ochronotic cartilage. The removal of the pigmented and impaired cartilage gave a characteristic pattern of osteoarthrotic remodelling. The resemblance of such remodelling to that seen in other joint diseases such as rheumatoid arthritis is discussed.

\section{References}

Č́nVeňanskÝ, J., SiŤAJ, S., AND URbáNeK, T. (1959) J. Bone Jt Surg., 41-A, 1169 (Alkaptonuria and chronosis)

LAGIER, R. (1971) "L'approche anatomo-pathologique du concept d'arthrose". C. R. Soc. franç. Traum. Chir. répar., 1968

O'Brien, W. M., Banfield, W. G., AND Sokoloff, L. (1961) Arthr. and Rheum., 4, 137 (Studies on the pathogenesis of ochronotic arthropathy)

—, La Du, B. N., AND Bunim, J. J. (1963) Amer. J. Med., 34, 813 (Biochemical, pathologic and clinical aspects of alcaptonuria, ochronosis and ochronotic arthropathy. Review of world literature (1584-1962))

SteIGER, U. (1963) $Z$. Rheumaforsch., 22, 367 (Ochronose)

VIRCHOw, R. (1866) Arch. path. anat., 37, 212 (Ein Fall von allgemeiner Ochronose der Knorpel und knorpelähnlichen Teile) 